\title{
Genetic influences on oestrous cyclicity in mice: evidence that cycle length and frequency are differentially regulated
}

\author{
J. F. Nelson ${ }^{1 *}$, K. Karelus ${ }^{1}$, L. S. Felicio ${ }^{2}$ and T. E. Johnson ${ }^{3}$ \\ ${ }^{1}$ Department of Physiology, University' of Texas Health Science Center, 7703 Floyd Curl Drive, San \\ Antonio, TX 78284-7756, USA; ${ }^{2}$ Department of Medicine, University of California at San \\ Francisco, USA; and ${ }^{3}$ Department of Psychology and Institute for Behavioral Genetics, University \\ of Colorado, Boulder, CO 80309, USA
}

\begin{abstract}
Summary. Studies in $\mathrm{C} 57 \mathrm{BL} / 6 \mathrm{~J}, \mathrm{DBA} / 2 \mathrm{~J}$ and $\mathrm{C} 3 \mathrm{H} / \mathrm{HeJ}$ mice and in two $\mathrm{F}$, hybrid strains ( $\mathrm{B} 6 \mathrm{D} 2 \mathrm{~F}_{1}$ and $\left.\mathrm{B} 6 \mathrm{C} 3 \mathrm{HF}_{1}\right) 2-5$ months old revealed marked genotypic differences among inbred strains. $\mathrm{C} 57$ mice had three times as many regular (3-6 days) cycles as DBA and $\mathrm{C} 3 \mathrm{H}$ mice, due largely to fewer pseudopregnant-like (7-14 day) cycles. C57 had longer regular cycles than DBA and $\mathrm{C} 3 \mathrm{H}$ mice. Although the frequencies of regular cycles of DBA and $\mathrm{C} 3 \mathrm{H}$ mice were similar, the cycles of $\mathrm{C} 3 \mathrm{H}$ mice were shorter than those of DBA mice. The results indicated that the genetic determinants of the frequency of regular cycles differ from those specifying cycle length. Frequency of regular cycles of $F_{1}$ hybrids was either intermediate between the parent strains $\left(\mathrm{B} 6 \mathrm{D} 2 \mathrm{~F}_{1}\right)$ or similar to the $\mathrm{C} 57$ strain $\left(\mathrm{B} 6 \mathrm{C} 3 \mathrm{HF}_{1}\right)$, suggesting that regular cycle frequency shows additive genetic variation in the former crosses, but mostly dominant variance in the latter background. Regular cycles were either shorter than in both parent strains $\left(\mathrm{B} 6 \mathrm{D} 2 \mathrm{~F}_{1}\right)$ or similar to one of them $\left(\mathrm{B} 6 \mathrm{C} 3 \mathrm{HF} \mathrm{F}_{1}\right)$, indicating heterosis and dominance for genes specifying short cycles. Although the lack of reciprocal crosses meant that maternal effects and possible genomic imprinting effects could not be assessed, these results reveal marked genetic influences on cycle length and frequency and suggest that some of the genes specifying these two traits differ.
\end{abstract}

Kelwords: genotype; oestrous cycle; pregnancy; mouse

\section{Introduction}

Ovulatory cycles differ markedly in frequency and regularity among individuals. This variation is present in women (Treloar et al., 1967) and has also been identified in female rodents (Nelson et al., 1982; Nelson \& Felicio, 1985). In rodents, genetic factors contribute to the variability in ovulatory cyclicity. For example, cycle length differs among mouse strains that vary in litter size (Barkley \& Bradford, 1981) or at the major histocompatibility complex (Lerner et al., 1988). However, the genetic specification of cycle variability is not well defined, and its physiological basis is poorly understood.

Recently, we reported marked genetic influences on the timing of puberty in several inbred mouse strains and began to define the nature of those influences (Nelson et al., 1990). It became apparent that strains exhibiting genetic variation in puberty might also show differences in cyclicity and thereby provide insight into the genetic specification of cyclicity. An understanding of the genetic basis for variation in cyclicity would also provide information for developing and testing models of the physiological regulation of cyclicity.

* Reprint requests. 
The objective of this study was to determine the influence of genotype on cycle frequency and length. Three inbred strains of mice and two of their $F_{1}$ hybrids were studied, the same strains used in the study of puberty.

\title{
Materials and Methods
}

\begin{abstract}
Animals and housing. All mice used in the study were first-generation offspring bred in our colony at the University of Texas Health Science Center. Parent C57BL/6J (C57), C3H/HeJ (C3H) and DBA/2J (DBA) mice were obtained from the Jackson Laboratory, Bar Harbor, ME, USA as 5-week-old virgins. The three inbred strains and two of the $F_{1}$ crosses $\left(\mathrm{C} 57\right.$ female $\times \mathrm{C} 3 \mathrm{H}$ male $\left(\mathrm{B} 6 \mathrm{C} 3 \mathrm{HF}_{1}\right) ; \mathrm{C} 57$ female $\times \mathrm{DBA}$ male $\left(\mathrm{B} 6 \mathrm{D} 2 \mathrm{~F}_{1}\right)$ ) were studied. This partial diallel design makes estimation of maternal and/or genomic imprinting effects impossible. The inbred strains were chosen because they are the parent stocks of the largest numbers of recombinant inbred (RI) lines. RI strains are powerful tools for identifying the numbers and locations of genes specifying identified traits (Bailey, 1971; Spearow, 1988).

Animals were kept in a limited-access colony of ageing mice maintained at $23-25^{\circ} \mathrm{C}$ on a $12 \mathrm{~h}$ light:12 h dark schedule. Mice were housed in transparent polycarbonate cages filled with hardwood chips (Beta Hardwood Chips, Northeastern Products, Warrensburg, NY, USA) and were allowed unlimited access to acidified water ( $\mathrm{pH} 2 \cdot 5)$ and food (Purina Rodent Laboratory Chow $\$ 5001$ : Ralston-Purina Co., St Louis, MO, USA). During mating, pregnancy and lactation, mice were fed a breeder diet (Purina $\$ 5015$ ).

Two females were paired with one male and monitored daily for the presence of vaginal plugs. Females with plugs were housed singly and monitored for deliveries beginning on Day 19 of gestation (Day I was the day a vaginal plug was found). Pups were weaned at 21 days of age, ear marked, weighed and housed three to a cage. There were 18 female and 6 male mice of each genotype. Mice of each genotype were obtained from six to eight litters, which ranged in size from five to nine pups. Litter-mates were never housed together. Animals in this study were housed on a single rack, one genotype per shelf. Cages containing males were interspersed between cages containing females to equalize pheromonal exposure, and genotypes were rotated through the shelves weekly to avoid placement bias. Body-weight was measured weekly.
\end{abstract}

Measurement of cyclicity. Oestrous cyclicity was monitored by daily vaginal lavage (Nelson et al., 1982) from 2 to 5 months of age, inclusive. Frequency of cyclicity (cycles per month) had peaked by 2 months in all strains and remained at peak levels throughout the period of measurement. Air-dried, Giemsa-stained smears were read and valid oestrous cycles were identified and counted and their lengths were determined by algorithms written for a microcomputer (Nelson et al., 1982 and L. S. Felicio, unpublished data). Cycles were subdivided into two classes: regular and pseudopregnant-like. Regular cycles were defined as cycles shorter than 7 days, and pseudopregnant-like cycles were defined as cycles longer than 6 days and shorter than 15 days. These criteria are based on several lines of evidence. First, the frequency distribution of cycle lengths was bimodal and the two resulting subpopulations exhibited cycle lengths of the aforementioned ranges (see Fig. 2). Secondly, cycles shorter than 7 days are associated with characteristic preovulatory increases in oestradiol (Nelson et al., 1981), preovulatory surges of luteinizing hormone and progesterone (Flurkey et al., 1982). In young adults, such cycles are usually ovulatory (Felicio et al., 1983; Gosden $e t$ al., 1983). Longer cycles are often associated with increased progesterone, an indicator of pseudopregnancy (Ryan \& Schwartz, 1977).

The individual mouse was the unit of measurement. For both regular and pseudopregnant-like cycles, two variables were measured: frequency (number of cycles $/ 4$ months) and length (in days). Preliminary analyses of these variables at 2-3 months and 4-5 months gave identical results; the data were pooled across the 4-month period to simplify the presentation.

Progesterone radioimmunoassay. Plasma was collected from a separate group of mice for measurement of plasma progesterone. Mice were monitored for a minimum of 2 cycles and blood was collected under anaesthesia $(2,2,2-$ tribromoethanol, $400 \mathrm{mg} / \mathrm{kg}$ body weight) from the retro-orbital sinus on the second or eighth day after pro-oestrus. These times were chosen to provide a measure of basal progesterone during the cycle (Day 2) and to determine whether the prolonged cycles were pseudopregnant-like cycles. Previous studies have shown that progesterone concentrations are at or near peak values on Day 8 of pseudopregnancy (Pepe \& Rothchild, 1974; Welschen $e t$ al., 1975). Progesterone was assayed as described by Flurkey et al. (1982).

Statistics. Data are expressed as the mean and the standard error of the mean (s.e.m.). Effects of genotype were assessed by one-way analysis of variance (ANOVA), followed by Duncan's multiple-range test (DMRT) to assess statistical significance of differences between specific genotypes. Heterosis $(\mathrm{h})$ was calculated as $\mathrm{h}=\mathrm{F}_{1}-\left[\left(\mathrm{P}_{1}+\mathrm{P}_{2}\right)\right]$ 2], where $F_{1}, P_{1}$ and $P_{2}$ are the means of the $F_{1}$, Parent ${ }_{1}$ and Parent ${ }_{2}$, respectively (Falconer, 1989). Percentage heterosis was calculated as $100\left(\mathrm{~h} /\left[\left(\mathrm{P}_{1}+\mathrm{P}_{2}\right) / 2\right]\right)$. Significance of heterosis was calculated using the $t$ statistic, where $t=h / V A R(h)$. Differences with $P$-values $\leqslant 0.05$ are considered statistically significant. 


\section{Results}

\section{Cycle frequency}

The frequency of regular cycles (Fig. 1) differed markedly among the inbred strains $(P<0 \cdot 001$, ANOVA). C57 mice had three times as many regular cycles as DBA and $\mathrm{C} 3 \mathrm{H}$ mice $(P<0.05$, DMRT). The numbers of regular cycles in DBA and C3H mice did not differ $(P>0.05$, DMRT). The frequency of pseudopregnant-like cycles also differed among inbred strains $(P<0.001$, ANOVA $)$ and was in large part inversely related to the frequency of regular cycles among those strains, as expected by the lack of independence of these measurements. C57 mice had, on average, only one pseudopregnant-like cycle during the 4 months of study, whereas DBA mice had nearly six pseudopregnant-like cycles, and $\mathrm{C} 3 \mathrm{H}$ were intermediate with four cycles $(P<0.05$, DMRT). These results indicate a strong genetic influence on cycle frequency.
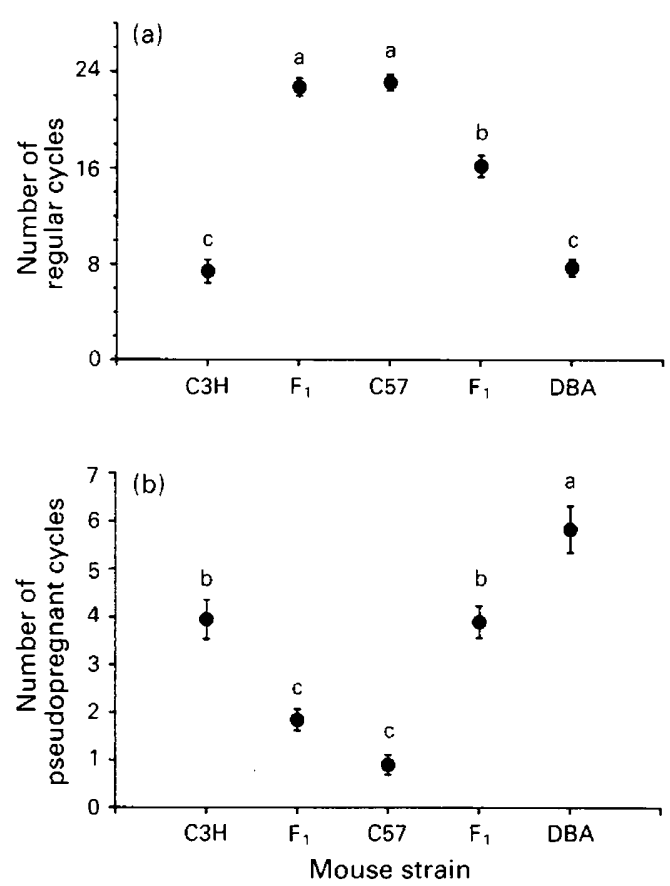

Fig. 1. Frequencies of (a) regular (3-6 days long) and (b) pseudopregnant-like (7-14 days long) cycles in mice $2-5$ months old in two of the $F_{1}$ crosses compared with their parental strains. $F_{1}$ strains are positioned between their two parental strains. Data are expressed as means \pm s.e.m. Some error bars are too small to be seen. Genotypes with different superscripts are significantly different $(P<0 \cdot 05$, Duncan's multiple-range test $)$.

In $\mathrm{B} 6 \mathrm{D} 2 \mathrm{~F}_{1}$ mice, the frequencies of regular and pseudopregnant-like cycles were intermediate with respect to those of the parents and not significantly different from their midparent means. This suggests that the variation in cycle frequency for these strains is specified by genes showing additive effects. By contrast, the frequencies of regular and pseudopregnant-like cycles of $\mathrm{B} 6 \mathrm{C}_{3} \mathrm{HF}_{1}$ mice were not different from those of the $\mathrm{C} 57$ parent strain and were significantly different from their respective midparent means $(P<0.001$ and $P<0.01$, respectively). This result suggests that the variation in cycle frequency for these two strains is specified by genes showing dominance, although maternal effects, or even genomic imprinting, cannot be ruled out. 


\section{Cycle length}

In all genotypes, the frequency distribution of cycle lengths was bimodal (Fig. 2). Depending on the genotype, short cycles had a modal length of 4 or 5 days, and long cycles had a modal length of 9,10 or 11 days. There was a variable number of cycles of 15 days or longer, presumably reflecting anovulatory intervals.

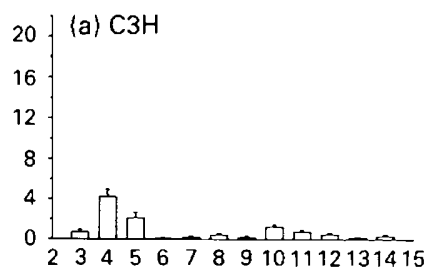

(b) B6C3F1
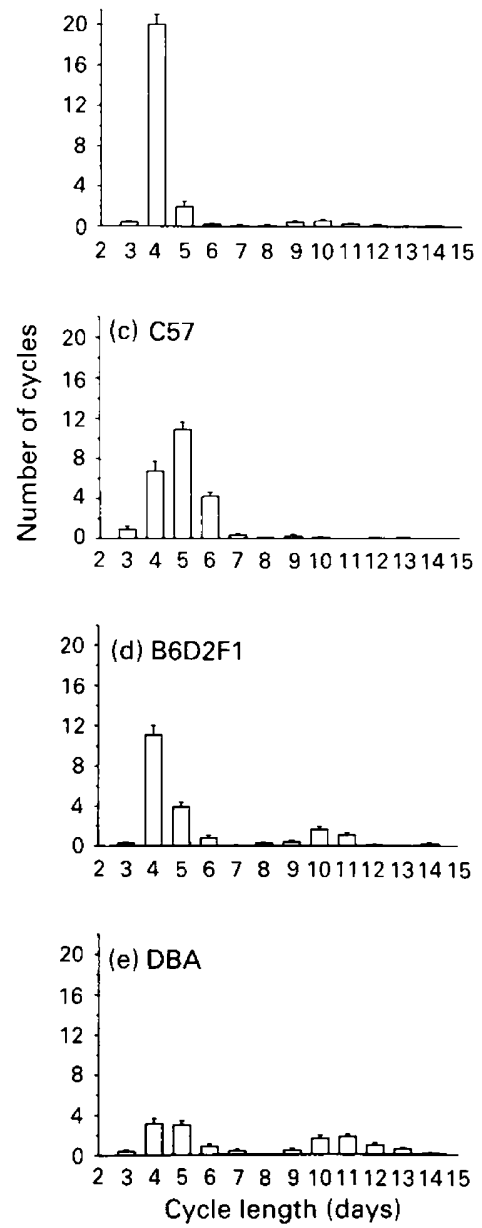

Fig. 2. Frequency distributions of cycle lengths in three inbred strains of mice (a, c and e) and two of their $F_{1}$ crosses (b and d) 2-5 months old. Data are expressed as means \pm s.e.m. 
To facilitate comparisons among the genotypes, the mean lengths of the regular (3-6 day) and pseudopregnant-like (7-14 day) cycles are presented in Fig. 3. The three inbred strains differed significantly in their regular cycle lengths $(P<0.001$, ANOva). C57 mice had the longest and $\mathrm{C} 3 \mathrm{H}$ mice had the shortest regular cycles $(P<0.05$, DMRT); DBA mice were intermediate in this regard. By contrast, C57 mice had the shortest pseudopregnant-like cycles $(P<0.05$, DMRT); the lengths of the longer pseudopregnant-like cycles of DBA and $\mathrm{C} 3 \mathrm{H}$ mice did not differ.

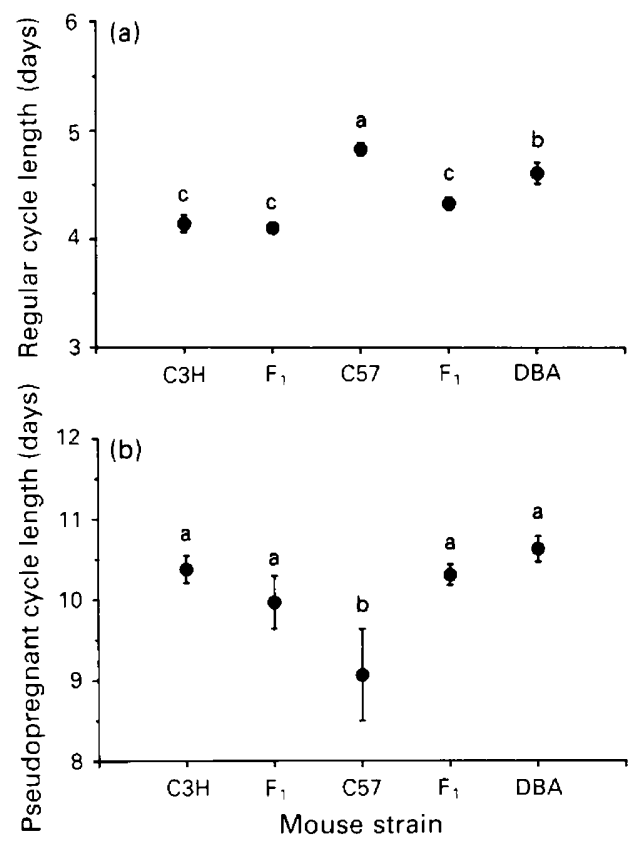

Fig. 3. Cycle lengths of (a) regular (3-6 days long) and (b) pseudopregnant-like (7-14 days long) cycles in mice 2-5 months old in two of the $F_{1}$ crosses compared to their parental strains. $F_{1}$ strains are positioned between their two parental strains. Data are expressed as means \pm s.e.m. Some error bars are too small to be seen. Genotypes with different superscripts are significantly different $(P<0 \cdot 05$, Duncan's multiple-range test).

In $\mathrm{B} 6 \mathrm{D} 2 \mathrm{~F}_{1}$ mice, the regular cycles were shorter (overdominant) than that of either parent strain $\left(P<0.05\right.$, DMRT); heterosis was $8 \%(P<0.001)$. In $\mathrm{B} 6 \mathrm{C} 3 \mathrm{HF}_{1}$ mice, the length of regular cycles was not different from the $\mathrm{C} 3 \mathrm{H}$ parent, indicating dominance of one or more genes specifying cycle length in that parent strain. Additional reciprocal crosses would be required to confirm these models and to rule out alternative explanations.

\section{Progesterone concentrations during pseudopregnant-like cycles}

To determine whether the pseudopregnant-like cycles displayed the increased concentrations of progesterone characteristic of such cycles, plasma concentrations of progesterone were measured on Day 8 of the cycle, when concentrations are maximal or near maximal in pseudopregnant rats (Pepe \& Rothchild, 1974; Welschen et al., 1975), and compared with basal concentrations on Day 2 of the cycle (Day 1 was pro-oestrus). Measurements were made in all strains except C57 mice, for which the frequency of pseudopregnant-like cycles was too low to obtain an adequate sample. Progesterone concentrations were significantly greater on Day 8 in all genotypes, than on Day 2 (Table 1). 
Table 1. Plasma progesterone concentrations on Days 2 and 8 after pro-oestrus in three inbred strains of mice and two of their $F_{1}$ crosses

\begin{tabular}{|c|c|c|}
\hline \multirow[b]{2}{*}{ Strain } & \multicolumn{2}{|c|}{ Progesterone $(\mathrm{ng} / \mathrm{ml})^{*}$} \\
\hline & Day 2 & Day 8 \\
\hline DBA & $10.4 \pm 0.7$ & $40.8 \pm 1.8$ \\
\hline $\begin{array}{l}\mathrm{B} 6 \mathrm{D} 2 \mathrm{~F}_{1} \\
\mathrm{C} 57^{\dagger}\end{array}$ & $9 \cdot 4 \pm 0.6$ & $33.7 \pm 3 \cdot 3$ \\
\hline $\mathrm{B} 6 \mathrm{C} 3 \mathrm{~F}_{1}$ & $15 \cdot 3 \pm 1 \cdot 7$ & $\begin{array}{l}27.9 \pm 2.8 \\
32.3+3.7\end{array}$ \\
\hline
\end{tabular}

*Data expressed as means \pm s.e.m., 12-2I determinations per group.

†Insufficient pseudopregnant-like cycles for sampling.

Values on Day 8 were significantly greater than those on Day $2(P<0.001$ ANOVA $)$.

\section{Discussion}

Marked variation was observed in the frequency and length of regular oestrous cycles among the five genotypes examined in this study. Cycle frequency differed threefold among inbred strains. Cycle length also differed: modal lengths ranged between 4 and 5 days for the three inbred strains. Analysis of the $F_{1}$ crosses revealed additive genetic influences on cycle frequency in one background and dominant effects in another genetic background. In contrast, the genetic influences on the length of regular cycles showed significant dominance or overdominance (heterosis) for short cycles in both $F_{1}$ backgrounds. However, the lack of a reciprocal-cross design means that maternal effects could not be estimated. Indeed, it is even possible that genomic imprinting (Haig \& Graham, 1991) could play a part in the specification of these traits. For example, Bander et al. (1989) reported paternal effects of egg susceptibility to attack by hyaluronidase and pronase, which they interpret as showing evidence of genomic imprinting. The number of genes specifying cycle frequency and length cannot be ascertained from these data; but the multiplicity of genetic influences identified in this study indicates that the regulation of these two traits is polygenic. The genetic relationships identified in this study may vary with different environmental conditions, since such environmental variables as diet (Nelson \& Felicio, 1984; Nelson et al., 1989) and housing density (Champlin, 1971) can markedly influence cyclicity in mice. With respect to housing density, however, the genetic differences appear robust; the differences seen in this study were maintained in singly housed mice in the four strains examined (J. F. Nelson, unpublished observations).

The genetic differences in the frequency of regular cycles are largely attributable to differences among the strains in proclivity for pseudopregnant-like cycles. Pseudopregnancies are frequently induced when female mice are housed in groups (Lee \& Boot, 1955; Dewar, 1959; Ryan \& Schwartz, 1977). This housing effect is apparently mediated by a stimulation of luteotrophic factors (Ryan \& Schwartz, 1977). Mice in the present study were housed three per cage, a number that has been shown to increase the frequency of pseudopregnant-like cycles in several strains (Champlin, 1971; Nelson et al., 1981). It thus seems likely that one or more components of the brain-pituitaryovarian loop involved in luteotrophic activity is enhanced in the two strains of mice that show a high incidence of pseudopregnancy. However, the strain differences in proclivity for pseudopregnantlike cycles do not solely reflect a genetic difference in response to multiple housing; preliminary studies indicate that the observed differences in pseudopregnant-like cycles are maintained even when $\mathrm{C} 57, \mathrm{C} 3 \mathrm{H}, \mathrm{B} 6 \mathrm{D} 2 \mathrm{~F}_{1}$ and $\mathrm{B} 6 \mathrm{C} 3 \mathrm{HF}_{1}$ mice are housed individually (DBA mice were not examined; J. F. Nelson, unpublished observations). 
Cycle frequency varies inversely with cycle length, provided that the incidence of acyclic intervals remains constant. Thus, in addition to the influence of pseudopregnant-like cycles on the frequency of regular cycles, genetic differences in the length of regular cycles could contribute to the strain differences in cycle frequency. However, there was no relationship between length and frequency of regular cycles among the genotypes. Indeed, among inbred strains, the strain with the highest frequency of cycles had the longest regular cycles. These results indicate that at least some of the genes, and therefore some of the physiological processes, specifying cycle length differ from those specifying cycle frequency. Further evidence for differential gene regulation of cycle length and cycle frequency was provided in the $F_{1}$ crosses. In the DBA/C57 crosses, genetic variance for cycle frequency was additive, but for cycle length it was overdominant. In the $\mathrm{C} 57 / \mathrm{C} 3 \mathrm{H}$ crosses, genetic variance for cycle frequency showed dominance of the C57 complement, but dominance of the $\mathrm{C} 3 \mathrm{H}$ complement was shown for cycle length.

This study has revealed marked genetic influences on the frequency and length of regular cycles and on the incidence of pseudopregnant-like cycles. Susceptibility of mice to irregular cyclicity is well known and this study indicates that susceptibility to pseudopregnancy plays an important role in the irregular cyclicity of mice. The striking strain differences in the incidence of apparent pseudopregnancy provide a useful means of studying the genetic and physiological basis for susceptibility to this common phenomenon in mice. Further genetic analyses, such as those obtained from studies of the $\mathrm{F}_{2}$ hybrids and recombinant inbreds derived from these strains, should help unravel the genetic specification of, and physiological basis for, the frequency and length of ovulatory cycles in mice. Mapping of loci for quantitative traits (Lander \& Botstein, 1989) has been successfully applied for several behavioural traits segregating in recombinant inbred lines (Neumann \& Seyfried, 1990) as well as for loci specifying length of life (Gelman et al., 1988). These analytical approaches should be applicable to studies of the reproductive variation observed in the present study.

We thank M. Bergman and J. Derminasyin for technical assistance and $\mathbf{J}$. DeFries for suggestions on statistical analysis. This work was supported by grants from the Medical Research Council of Canada and funds from the University of Texas Health Science Center at San Antonio (J. F. Nelson) and USPHS AG 08322 and AG 00369 (T. E. Johnson).

\section{References}

Bailey, D.W. (197I) Recombinant-inbred strains: an aid to finding identity. linkage, and function of histocompatibility and other genes. Transplantation 11, 325-327

Bander, S.A.A., Watson, S.C. \& Shire, J.G.M. (1989) Paternal inheritance of egg traits in mice: a case of genomic imprinting. Genet. Res. 54, 213219.

Barkley, M.S. \& Bradford, G.E. (1981) Estrous cycle dynamics in different strains of mice. Proc. Soc. exp. Biol. Med. 167, 70-77.

Champlin, A.K. (1971) Suppression of oestrus in grouped mice: the effects of various densities and the possible nature of the stimulus. $J$. Reprod. Fert. 27, 233 241.

Dewar, A.D. (1959) Observations on pseudopregnancy in the mouse. J. Endocr. 18, 186-190.

Falconer, D.S. (1989) Introduction to Quantitative Genetics, 3rd edn, 438 pp., Longman Scientific and Technical, Harlow, UK.

Felicio, L.S., Nelson, J.F., Gosden, R.G. \& Finch, C.E. (1983) Restoration of ovulatory cycles by young ovarian grafts in aging mice: potentiation by longterm ovariectomy decreases with age. Proc. natl Acad. Sci. USA 80, 60766080.
Flurkey, K., Gee, D.M., Sinha, Y.N., Wisner, J.R. \& Finch, C.E. (1982) Age effects on luteinizing hormone, progesterone and prolactin in proestrous and acyclic C57BL/6J mice. Biol. Reprod. 26, 835846 .

Gelman, R., Watson, A., Bronson, R. \& Yunis, E. (1988) Murine chromosomal regions correlated with longevity. Genetics 118, 693-704.

Gosden, R.G., Laing, S.C., Felicio, L.S., Nelson, J.F. \& Finch, C.E. (1983) Imminent oocyte exhaustion and reduced follicular recruitment mark the transition to acyclicity in aging C57BL/6J mice. Biol. Reprod. 28, 255-260.

Haig, D. \& Graham, C. (1991) Genomic imprinting and the strange case of the insulin-like growth factor II receptor. Cell 64, 1045-1046.

Lander, E.S. \& Botstein, D. (1989) Mapping Mendelian factors underlying quantitative traits using RFLP linkage maps. Genetics 121, 185-199.

Lerner, S.P., Anderson, C.P., Walford, R.L. \& Finch, C.E. (1988) Genotypic influences on reproductive aging in inbred female mice: effects of $\mathrm{H}-2$ and non-H-2 alleles. Biol. Reprod. 38, 10351043.

Downloaded from Bioscientifica.com at 04/26/2023 11:06:20AM 
Nelson, J.F. \& Felicio, L.S. (1984) Dietary modulation of estrous cyclicity in singly and multiply housed C57BL/6J mice. Lab. Anim. Sci. 34, 173-176.

Nelson, J.F. \& Felicio, L.S. (1985) Reproductive aging in the female: an etiological perspective. Rev. Biol. Res. Aging 2, 251-314.

Nelson, J.F., Felicio, L.S., Osterburg, H.H. \& Finch, C.E. (1981) Altered profiles of estradiol and progesterone associated with prolonged estrous cycles and persistent vaginal cornification in aging $\mathrm{C} 57 \mathrm{BL} / 6 \mathrm{~J}$ mice. Biol. Reprod. 24, 784-794.

Nelson, J.F., Felicio, L.S., Randall, P.K., Sims, C. \& Finch, C.E. (1982) A longitudinal study of estrous cyclicity in aging $\mathrm{C} 57 \mathrm{BL} / 6 \mathrm{~J}$ mice. I. Cycle frequency, length and vaginal cytology. Biol. Reprod. 27, $327-339$.

Nelson, J.F., Goodrick, G., Karelus, K. \& Felicio, L.S. (1989) Longitudinal studies of estrous cyclicity in C57BL/6J mice: III. Dietary modulation declines during aging. Mech. Age. Dev. 48, 73-84.

Nelson, J.F., Karelus, K., Felicio, L.S. \& Johnson, T.E. (1990) Genetic influences on the timing of puberty in mice. Biol. Reprod. 42, 649-655.

Neumann, P.E. \& Seyfried, T.N. (1990) Mapping of two genes that influence susceptibility to audiogenic seizures. Behav. Genet. 20, 307-323.
Pepe, G. \& Rothchild, I. (1974) A comparative study of serum progesterone levels in pregnancy and in various types of pseudopregnancy in the rat. Endocrinology 95, 265-279.

Ryan, K.D. \& Schwartz, N.B. (1977) Grouped female mice: demonstration of pseudopregnancy. Biol. Reprod. 17, 578-583.

Spearow, J.L. (1988) Major genes control hormoneinduced ovulation rate in mice. $J$. Reprod. Fert. 82, 787-797.

Treloar, A.E., Boynton, R.E., Behn, B.G. \& Brown, B.W. (1967) Variation of the human menstrual cycle through reproductive life. Int. J. Fert. 12, 77-126.

van der Lee, S. \& Boot, L.M. (1955) Spontaneous pseudopregnancy in mice. Acta Physiol. Pharm. 4, 442-443.

Welschen, R., Osman, P., Dullaart, J., De Greef, W.J., Uilenbroek, J.Th.J. \& De Jong, F.H. (1975) Levels of follicle-stimulating hormone, luteinizing hormone, oestradiol-17beta and progesterone, and follicular growth in the pseudopregnant rat. J. Endocr. 64, $37-47$.

Received 24 December 1990 